\title{
BIBLIOGRAFIA
}

\section{Bibliografía de Manuel José Othón}

\author{
$(1858$ - 1906)
}

NOTA PRELIMINAR

HASTA ahora no se ha publicado una bibliografía de Manuel José

Othón. Debido al creciente interés por el poeta mexicano y las excelentes ediciones recientes de su obra, he querido dar a conocer mi bibliografía del ilustre potosino. No se considera completa, ni mucho menos; pero representa una tentativa hecha para reunir, en forma accesible, todos los datos posibles sobre Othón. Esta bibliografía es el resultado de mis investigaciones en México, para un estudio escrito en inglés: Manuel José Othón, Nature Poet of Mexico.

La primera parte de la bibliografía comprende toda la obra conocida de Manuel José Othón: sus poesías, subdivididas en colecciones y poesías sueltas, sus dramas, sus cuentos cortos y artículos. En la segunda parte se hallan los estudios críticos y biográficos del poeta.

No se han incluído las antologías en que aparecen poesías de Othón, por ser innumerables.

$$
\begin{gathered}
\text { BernICE UdICK, } \\
\text { University of Wyoming. }
\end{gathered}
$$


PRIMERA PARTE - OBRAS DE MANUEL JOSE OTHON

A. PoEsia.

\section{Colecciones}

1 Breve antología lírica. Prólogo y selección de Jesús Zavala. Edición de la Universidad Potosina Autónoma, 1943. 105 pp., "Esquema biográfico", índice, colofón.

Colofón: Se imprimieron mil ejemplares: Trescientos en papel ministro y setecientos en revolución. México, D. F.

Contiene 17 poemas.

2 La flauta de Pan (Antología mínima). Selección y prólogo de Jesús Zavala. Editor: B. Costa-Amic, México, 1945. 40 pp., índice, colofón. (Cuadernos de poesía, 2.)

Colofón: Se terminó de imprimir el día primero de febrero de 1945, en los talleres de B. Costa-Amic, Editor-Impresor, en la ciudad de México.

Contiene 8 poemas.

3 Obras completas. Poesía. Prosa. Teatro. Edición preparada por Jesús Zavala. Editorial Nueva España, S. A., México, [1945]. (Colección Atenea, 18.) [ix]-lxxi, [1]-1067 pp., índice.

Contiene un prólogo por Jesús Zavala: I. Noticia biográfica. II. El poeta. III. El prosista. IV. El autor general. V. Notas.

Poesías. "Violetas", "Poemas y leyendas", "Poemas internos", "Poemas rústicos", "La emoción dispersa".

Prosa.

"Cuentos y novelas cortas".

Teatro.

Apéndices.

Estudios: Don Manuel José Otbón, por Victoriano Agüeros; Recuerdos de Otbón, por Luis G. Urbina; Los "Poemas rísticos" de M. J. Otbón, por Alfonso Reyes.

4 Obras de Manuel José Othón. Publicaciones de la Secretaría de Educación Pública, México, 1928. 2 tomos.

Tomo I. Poesía. 264 pp., indice.

Contiene: Victoriano Agüeros, Prólogo a la colección de sus Poesías publicadas en 1880, pp. [ix]-xiv; José López-Portillo y 
Rojas, Elogio de Manuel José Othón, pp. [xv]-xli; Luis G. Urbina, Manuel José Otbón en la Ciudad de México, pp. [xliii]xlv; Luis G. Urbina, Anécdotas de la intimidad, pp. [xlvii]-lii; Jesús Urueta, A Manuel José Othón. Palabras pronunciadas en la velada que organizó la Revista moderna, en el Teatro del Renacimiento, la noche del 4 de enero de 1907, pp. [liii]-lxii; un estudio, sin título, por Alfonso Reyes, pp. 1-14.

"Poesías antiguas, 1877 a 1880", "Poesías antiguas, 1878 a $1895 "$, "Poemas rústicos", "Ultimas producciones".

Tomo II. Prosa. 379 pp., indice.

"Cuentos de espantos", "Novelas rústicas", "Novelas cortas", "Fragmentos tomados de un libro de apuntes", "Teatro".

5 Paisaje. Prólogo y selección de Manuel Calvillo. México, Ediciones de la Universidad Nacional Autónoma, 1944, ix-xxxviii, 169 pp., 10 (notas, índice, colofón). (Biblioteca del Estudiante Universitario, 50.)

Colofón: En la Imprenta Universitaria, bajo la dirección de Francisco Monterde, fué impreso este libro que ilustró Julio Prieto. Contiene la mayor parte de los Poemas rústicos y algunas de las últimas producciones.

6 Poemas escogidos. Selección de Agustín Loera y Chávez. México, Cultura, t. II, núm. 4. Imprenta Victoria, 1917.78 pp., índice.

7 Poemas rústicos de Manuel José Othón, 1890-1902. México, Aguilar Vera y Comp., Editores, 1902. 3 1., iv, [13]-152 pp., índice, retrato.

8 Poemas rústicos. México, Editorial Porrúa, S. A., 1944. 180 pp., colofón. (Colección de Escritores Mexicanos, 5.)

Colofón: Se acabó de imprimir este libro el día 20 de octubre de 1944, en los talleres de la Editorial Stylo, en la Ciudad de México. Se tiraron 100 ejemplares en papel especial, numerados del 1 al 100.

Contiene los Poemas rústicos y las últimas producciones.

9 Poemas y cuentos. Selección y prólogo de Miguel Bustos Cerecedo. México, Secretaría de Educación Pública, 1945. 87 pp., índice, colofón. (Biblioteca Enciclopédica Popular, 39.)

Colofón: Este libro, que corresponde al tomo 39 de la Biblioteca Enciclopédica Popular de la Secretaría de Educación Pública, terminó de editarse el día 26 de enero de 1945.

Contiene 15 poemas, 3 novelas cortas y un artículo por Lorenzo Turrent Rozas, Manuel José Otbón. ¿Colono mental?, pp. 84-87. Se lee en la portada: Manuel José Othón. (Poemas y cuentos.) 
10 Poesías. 1880. Prólogo de Victoriano Agüeros. - Victoriano Agüeros, Don Manuel José Othón. (Prólogo a la colección de sus Poesías publicadas en 1880), publicada en El Tiempo, edición literaria, t. I (1883-1884), núm. 32 (24 de febrero de 1884), pp. 383387.

11 Ultimas poesias. San Luis Potosí, Bruno E. García, 1888.-Francisco de A. Castro, Manuel José Othón. En El Estandarte, San Luis Potosí, año xxm, núm. 4774 (8 de diciembre de 1906).

\section{Poesías sueltas.}

Nota: Entiéndase que en esta bibliografía todas las publicaciones citadas son de México, D. F., a excepción de La república literaria de Guadalajara, y El Estandarte y El Contemporáneo, diarios de San Luis Potosí.

Obras completas se refiere a la edición de Jesús Zavala. Véase el núm. 3.

12 . Primera línea: "Afilador que paseas..." En El Contemporáneo, t. XII, núm. 2526 (18 de marzo de 1907).

12 a [- $[$. Publicada con el título El afilador en Obras completas.

13 . Primera línea: "Alto sobre la cima de algún monte..." En Obras, 1928, t. $\mathrm{x}$.

13 a $[-[-]$. Publicada con el título Alto, sobre la cima ... en Obras completas.

14 - Primera línea: "La vi pasar. Los últimos fulgores ..." En El Contemporáneo, t. XIr, núm. 2526 (18 de marzo de 1907).

En Obras completas, parte II de un grupo de poesias, con el título Melodias.

15 Primera línea: "Si los suspiros son aire..." En El Mundo (2 de junio de 1895).

15 a $\left[-\frac{}{\text { pletas. }}\right]$. Publicada con el título En un abanico en Obras com-

16 A Ambrosio Ramírez. Después de leer su traducción de Horacio. En La República Literaria, año Iv, t. v (1889-1890), p. 32.

Parte de Sonetos paganos. Véase el núm. $164 \mathrm{a}$.

17 A Augusto Comte. En Obras completas. 
18 A Cervantes. En El Album de la Mujer, año II, núm. 17 (27 de abril de 1884), p. 253.

$18 \mathrm{a}$ [- ]. Publicada con el título Al autor del Quijote en El Tiempo Ilustrado, año v, núm. 230 (21 de mayo de 1905), p. 310.

No se incluye en ninguna colección de la obra de Othón.

19 A Clearco Meonio. I. La selva. II. La musa. III. Los poetas. (Inéditos.) En El Estandarte, año x, núm. 1308 (28 de noviembre de 1894).

En Poemas rústicos y Obras completas.

19a - En La Revista Azul, t. Iv, núm. 23 ( 5 de abril de 1896), p. 359.

Partes I y II.

$19 \mathrm{~b} \longrightarrow$. En Artes y Letras, año v, núm. 113 (23 de mayo de 1909).

20 Adiós al poeta. En El Contemporáneo, t. Ix, núm. 1696 (7 de abril de 1904).

Parte XXII de Nocbe rústica de Walpurgis. Véase el núm. 117.

21 A Elena Padilla. En Obras completas.

22 A Estber. En Obras completas.

23 A la actriz española Maria Rodríguez. En Obras completas.

$23 a$ [- $]$. Publicada con el título $A$ una actriz, en Obras, 1928, t. $\mathrm{x}$.

24 A la juventud. Oda leída en una distribución de premios del Instituto. En Obras completas.

25 A la memoria de Selgas. Elegía. En El Imparcial, año I, núm. 6 (6 de agosto de 1882).

No se incluye en ninguna colección de la obra de Othón.

26 A la Sociedad Alarcón. En Obras completas.

27 Al autor del Quijote. Véase el núm. $18 \mathrm{a}$.

28 Alborada. En El Contemporáneo, año Ix, núm. 1925 (23 de febrero de 1905).

Las primeras cuatro estrofas de Angelus domini. Véase el núm. 37:

29 Al general Diaz. En El Tiempo Ilustrado, año va, núm. 46 (11 de noviembre de 1906), p. 651.

En Obras completas.

30 A los que estudian. Oda. Leída en la distribución de premios del Instituto. En Memoria de los trabajos de la Junta Directiva de Es- 
tudios del Instituto Científico y Literario, San Luis Potosí, Imprenta de Dávalos, 1881.

En Obras completas.

31. A Maria. En su álbum. En Obras completas.

32 A México. En El Album de la Mujer, año v, t. Ix, núm. 8 (21 de agosto de 1887), p. 58 .

32a [- - Publicada con el título Cuaubtémoc. A México. En Obras completas.

33 A mi esposa. En Obras completas.

34 A mi madre. En Obras completas.

34a $[-]$. Publicada con el título Tristezas. A mi madre. En Obras, 1928.

35 Los amores de la tierra. En Obras completas.

36 Amores eternos. Don Quijote-Dulcinea. En El Album de la Mujer, año II, núm. 24 (15 de junio de 1884), p. 354.

En Obras completas.

362 [- $]$. Publicada con el título Don Quijote-Dulcinea en La República Literaria, año III, t. IV (marzo de 1888-1889), pp. 569570.

36b En El Contemporáneo, t. vin, núm. 1353 (26 de octubre de 1902).

36c En El Estandarte, año XxI, núm. 4436 (13 de octubre de 1905).

37 Angelus domini. En La Revista Azul, t. I, núm. 16 (6 de mayo de 1894), pp. 243-244.

En Poemas rústicos y Obras completas.

37a [- $]$. Fragmento con el título Infinito y poderoso, publicado en El Estandarte, año xvir, núm. 3174 (29 de mayo de 1901).

$37 \mathrm{~b}$ [-]. Fragmento con el título Infinito y poderoso, publicado en El Tiempo Ilustrado, t. I, núms. 27 y 28 (1 $1^{\circ}$ y 8 de julio de 1901), pp. 313 y 326.

La segunda es la versión corregida.

37c En Revista Moderna, año $\mathrm{v}$, núm. 12 (segunda quincena de junio de 1902), pp. 184-186.

$37 \mathrm{~d}$ [-]. Fragmento con el título Alborada publicado en El Contemporáneo, año xx, núm. 1925 (23 de febrero de 1905). 
37e En Repertorio americano, San José de Costa Rica, año XXI, núm. 894, t. XxxviI, núm. 14 ( 8 de junio de 1940), p. 219.

38 Anbelo. En Obras completas.

39 A Primo Feliciano Velázquez. En Obras completas.

40 A través de la lluvia. En El Mundo, t. 1, núm. 23 (6 de junio de $1897)$, p. 384.

En Poemas rísticos y Obras completas.

40a En El Estandarte, año xirr, núm. 2020 (11 de junio de 1897).

40b En El Contemporáneo, t. m, núm. 431 (9 de enero de 1898).

41 A una actriz. Véase el núm. 23a.

42 A una poetisa. En Obras completas.

43 A un traductor de Horacio. Parte de Sonetos paganos. Véase el núm. 164.

44 Ausencia. Cantares. En Obras completas.

45 Bajo el sol. En Obras completas.

Véase el núm. 128c.

46 Blanca de nieve. Cuento. A mis hermanas María e Isabel. En El Universal, t. xII, núm. 75 (31 de marzo de 1895).

En Obras completas.

47 La canción del otoño. En El Estandarte, año xv, núm. 2717 (5 de noviembre de 1899).

En Poemas rústicos y Obras completas.

47a - En El Universal, t. I, núm. 10 (12 de noviembre de 1899).

47b - En El Tiempo Ilustrado, t. I, núm. 4 (21 de enero de 1901), p. 41.

$47 \mathrm{c} \longrightarrow$. En El Contemporáneo, t. vi, núm. 1262 (8 de diciembre de 1901).

47d En El Estandarte, año xvm, núm. 3339 (31 de diciembre de 1901).

48 Canto de las estrellas. En El Estandarte, año xxi, núm. 4327 (28 de mayo de 1905).

Parte VII, Las estrellas, de Nocbe rústica de Walpurgis. Véase el núm. 117.

49 El canto de Lodbrok. En Obras completas. 
S0 Canto del regreso. En El Estandarte, año xx, núm. 4116 (10 de septiembre de 1904), con la dedicatoria: "A mi amigo muy querido Blas Escontría. Homenaje de gratitud sincera y acendrado afecto." Al final: "Recitada por su autor en el gran Teatro de la Paz, a invitación de la Junta de Damas Potosinas, organizadoras del Concierto verificado la noche del 28 de agosto de 1904."

En Obras completas.

50a - En El Contemporáneo, t. Ix, núm. 1797 (21 de septiembre de 1904).

$50 \mathrm{~b}-$ En El Contemporáneo, t. Ix, núm. 1925 (23 de febrero de 1905).

50c En Revista de Revistas, año xxvi, núm. 1379 (25 de octubre de 1936).

51 Canto mupcial. A Ladislao Gómez Palacio y Lupe Díaz Conder. En Revista Moderna, año II, núm. 24 (segunda quincena de diciembre de 1900), pp. 378-379.

En Poemas rústicos y Obras completas.

$51 \mathrm{a}-$ En El Tiempo Ilustrado, t. 1 , núm. 1 ( $1^{\circ}$ de enero de 1901), p. 11.

s1b . En El Estandarte, año xvII, núm. 3083 (2 de febrero de 1901).

S1c En El Contemporáneo, t. Ix, núm. 1991 (18 de mayo de 1905).

51d [-]. Fragmento con el título Nupcial, publicado en El Estandarte, año XXI, núm. 4335 (18 de junio de 1905).

51e En El Tiempo Ilustrado, año vi, núm. 4 (21 de enero de 1906), p. 71.

52 Cineraria. En Obras completas.

53 La civilización. En Obras completas.

54 Crepúsculos. Al amanecer y Al caer la tarde. En La Repuiblica Literaria, año III, t. IV (1888-1889), pp. 773-774.

En Poemas rústicos y Obras completas.

54a - En El Tiempo, semanario ilustrado, t. II, núm. 145 (S de octubre de 1905), pp. 514-515.

55. Cristóbal Colón. En Obras completas.

56 La cruz sola. En El Imparcial, año In, núm. 146 (28 de enero de 1883).

En Obras completas. 
56a - En El Album de la Mujer, año n, núm. 14 (6 de abril de 1884), pp. 215-216.

56b - En El Mundo Ilustrado, t. I, núm. 14 (3 de abril de 1898).

56c - En El Contemporáneo, t. vir, núm. 1299 (20 de abril de 1902).

56d - En El Estandarte, año xvin, núm. 3481 (29 de junio de 1902).

56e - En El Tiemp̣o Ilustrado, año vi, núm. 37 (9 de septiembre de 1906), p. 501 .

S6f - En Artes y Letras, año vII, núm. 212 (16 de abril de 1911).

57 Cuaubtémoc. Véase el núm. 32a.

58 Delirio. En Obras completas.

59 Del Obispo Caramuel, citado por el P. Tosca. En Obras completas.

59a [- ]. En Obras, 1928, t. I, con el título (Del Obispo Caramuel, citado por el P. Tosca).

60 De un poema. En Obras completas.

Véase el núm. $82 \mathrm{a}$.

61 Don Quijote-Dulcinea. Véase el núm. 36a.

62 El duelo. En El Contemporáneo, t. xm, núm. 2548 (18 de abril de 1907).

En Obras completas.

62a . En El Contemporáneo, t. xv, núm. 2890 (11 de junio de 1908).

63 ¡Duerme! En Obras completas.

64 Elegía. A la memoria del maestro don Rafael Angel de la Peña. En El Estandarte, año xxrr, núm. 4752 (13 de noviembre de 1906). En Obras completas.

64a - En El Contemporáneo, t. xI, núm. 2425 (14 de noviembre de 1906).

64b - En El Tiempo Ilustrado, año vI, núm. 47 (18 de noviembre de 1906 ), p. 667.

$64 \mathrm{c} \longrightarrow$. En Revista Moderna, t. vII, núm. 3 (noviembre de 1906), pp. $179-180$.

64d - En Artes y Letras, año III, núm. 29 (diciembre de 1906). 
$64 \mathrm{e}$ - En Revista de Revistas, año Xxvi, núm. 1379 (25 de octubre de 1936).

65 Elegía. Canto tercero de Poema de vida. En Obras completas. Véase el núm. 142.

66 Elegía. En la muerte del licenciado don Marcelino Castro. En Obras completas.

67 Elegía. En la muerte del señor don Joaquín García Icazbalceta. En Obras completas.

68 Elegía. En la muerte de Manuel Gutiérrez Nájera. En El Universal, t. XII, núm. 40 (17 de febrero de 1895).

En Obras completas.

$68 \mathrm{a}$ - En El Estandarte, año xr, núm. 1370 (20 de febrero de 1895$)$.

68b - En La Revista Azul, t. II, núm. 17 (24. de febrero de 1895), pp. 268-269.

69 Ella. (De Lord Byron.) En Obras completas.

70 En el desierto. Idilio salvaje. En El Mundo Ilustrado, año XIII, t. $\mathrm{n}$, núm. 25 (16 de diciembre de 1906).

En Obras completas con el título Idilio salvaje.

$70 \mathrm{a} \longrightarrow$. En El Estandarte, año xxII, núm. 4781 (19 de diciembre de 1906).

$70 \mathrm{~b} \longrightarrow$. En El Contemporáneo, año xir, núm. 2454 (20 de diciembre de 1906).

$70 \mathrm{c}$ - A Alfonso Toro. En Revista Moderna, t. vIr, núm. S (enero de 1907), pp. 281-288.

$70 \mathrm{~d}-$ En Revista de Revistas, año xxvi, núm. 1379 (25 de octubre de 1936).

71 En la inauguración del Teatro de la Paz. En El Estandarte, año x, núm. 1291 ( 7 de noviembre de 1894). En Obras completas.

72 En un abanico. Véase el núm. 15a.

73 En una fiesta de obreros. En Obras completas.

74 Envio. Es el último soneto En el desierto. Idilio salvaje. Véase el núm. 70.

75 Epitalamio. Canto segundo de Poema de vida. Véase el núm. 142.

76 La estatua de carne. En Obras completas. 
77 Este dia. En Obras completas.

78 Una estepa del Nazas. En El Contemporáneo, t. vir, núm. 1329 (3 de agosto de 1902).

Parte II de Frondas y glebas. Véase el núm. 83.

79 Flores tristes. En Obras completas.

80 Flos-Mors. En Obras completas.

81 Fragmento. (De Lord Byron.) En Obras completas.

82 Fragmento de un poema inédito. En El Mundo Ilustrado, t. I (23 de julio de 1905).

82a [- $]$. Publicada con el título De un poema, en Obras, 1928, t. I, y Obras completas.

83 Frondas y glebas. A Clearco Meonio. I. Orillas del Papaloapan. II. Una estepa del Nazas. En Revista Moderna, año III, núm. 7 (primera quincena de abril de 1900), p. 107.

En Poemas rísticos y Obras completas.

83 a Ln El Tiempo, semanario ilustrado, t. III, núm. 145 ( 5 de octubre de 1905), pp. 514-515.

$83 \mathrm{~b} \longrightarrow$. En El Tiempo, año xxIv, núm. 7837 (2 de diciembre de 1906).

$83 \mathrm{c}$ - En Revista de Revistas, año xxvi, núm. 1379 (25 de octubre de 1936).

84 Frons in mare. En la muerte de la niña Amelia Aguayo. En El Mundo, t. I, núm. 2 (9 de enero de 1898), p. 29.

85 Himno a lturbide. En Obras completas.

86 Himno de los bosques. En El Correo de San Luis, San Luis Potosí (abril de 1891).

-Jesús Zavala. Génesis del "Himno de los bosques", en Revista de Revistas, año xxvi, núm. 1379 (25 de octubre de 1936). En Poemas rústicos y Obras completas.

$86 a$ - En El Mundo Literario Ilustrado (de Juan de Dios Peza), t. I, núm. 21 (14 de junio de 1891), pp. 6-7.

86b - En El Renacimiento (8 de abril de 1894), pp. 224-226.

86c. - En El Mundo, t. I, núm. 11 (13 de marzo de 1898).

86d En Revista Moderna, año II, núm. 2 (febrero de 1899), pp. 33-35. 
86 e Edición de "Capullos". San Luis Potosí (28 de noviembre de 1908). 18 pp.

Al final: Tip. de la Escuela I. Militar, dirigida por A. B. Cortés. No hay portada. P. 1 es retrato de Manuel José Othón.

Lleva el título erróneo: El bimno de los bosques.

$86 \mathrm{f} \longrightarrow$. En Revista de Revistas, año xxvi, núm. 1379 (25 de octubre de 1936).

$86 \mathrm{~g} \longrightarrow$. En Repertorio Americano, San José de Costa Rica, año xIx, núm. 842, t. xxxv, núm. 10 (12 de marzo de 1938), pp. 153154.

87 Historia de un beso. En Obras completas.

88 Hoja de álbum. En Obras completas.

89 Ideal. En Obras completas.

90 Idilio. Canto primero de Poema de vida. Véase el núm. 142.

91 Idilio salvaje. Véase el núm. 70.

92 Imitación. I. Noches de junio. (Víctor Hugo.) II. Jamás. (Bécquer.) En Obras, 1928, t. I.

Véanse los núms. 118 y 98.

93 In excelsis. En El Estandarte, año xxI, núm. 4614 (26 de mayo de 1906).

En Obras completas.

93a - A Rubén M. Campos. En Revista Moderna, t. vi, núm. 5 (julio de 1906), p. 326.

93b - En El Estandarte, año xxIn, núm. 4729 (16 de diciembre de 1906).

$93 \mathrm{c} \longrightarrow$. En El Mundo Ilustrado, año xIII, t. II, núm. 25 (16 de diciembre de 1906).

94 Infinito y poderoso. Véase el núm. 37 a y el núm. $37 \mathrm{~b}$.

95 In terra pax. A la memoria de Marcos Vives. En El Estandarte, año $\mathrm{XV}$, núm. 2505 (14 de febrero de 1899).

En Poemas rústicos. En Obras, 1928, t. I, con el título erróneo Interna pax. En Obras completas.

96 Intima. En La Revista Azul, t. II, núm. 1 (5 de mayo de 1895), p. 14.

En Poemas rústicos y Obras completas, con el título Voz interna.

96a - En El Estandarte, año xvmr, núm. 3540 (14 de septiembre de 1902). 
96b En El Estandarte, año xxII, núm. 4570 (29 de mayo de 1906).

96c - En El Estandarte, año xxII, núm. 4645 (5 de julio de 1906).

96d - En El Tiempo Ilustrado, año vi, núm. 33 (12 de agosto de 1906 , p. 445 .

$96 \mathrm{e} \longrightarrow$. En El Contemporáneo, año xII, núm. 2448 (6 de diciembre de 1906).

97 Invocación. Parte I de los Poemas rústicos.

98 ¡Jamás! (Imitación de Bécquer.) En Obras completas.

99 El lago de los muertos. En Obras, 1928, t. I, con la nota: "... copiada del periódico El Estandarte, de San Luis Potosí, correspondiente al 13 de julio de 1890 ".

En Obras completas.

100 Lasciate ogni speranza. En Obras completas.

101 La libertad. En Obras completas.

102 Lobreguez. En Revista Moderna, año Iv, núm. 14 (segunda quincena de julio de 1901), pp. 222-223.

En Poemas rústicos y Obras completas.

102a [una leyenda inédita. A José de la Vega Serrano. En El Estandarte, año $x$, núm. 1336 ( 5 de enero de 1895).

$102 \mathrm{~b} \longrightarrow$. En El Estandarte, año XvII, núm. 3257 ( 7 de septiembre de 1901).

102c En Revista Moderna, t. Ix, núm. 2 (octubre de 1907), pp. 97-98.

103 La loca de las olas. En Obras completas.

104 Macbeth. Fragmento de un arreglo del drama de Shakespeare a la escena española. En La Revista Azul, t. III, núm. 16 (18 de agosto de 1895), p. 246.

En Obras completas.

105 ¡Madre! En un álbum. En Obras completas.

106 Matinal. Parte I de Procul negotiis. Véase el núm. 147.

107 Melodías. En Obras completas.

108 El mendigo. En Obras completas. 
109 Meridies. Parte I de Paisajes. Véase el núm. 131.

110 Mi pueblo. A la señora doña Concepción Gimeno de Flaquer, inspirada escritora española. En El Album de la Mujer, año II, núm. 10 (9 de marzo de 1884), pp. 147-148.

En Obras completas.

$110 \mathrm{a}$. En La Repuiblica Literaria, año II, t. IV (1888-1889), pp. 306-308.

$110 \mathrm{~b} \longrightarrow$. En El Contemporáneo, año xIx, núm. 3144 (29 de abril de 1909).

111 Mis versos. (De V. Hugo.) En Obras completas.

112 Mi virgen. En Obras completas.

113 . Las montañas épicas. A mis amigos de Monterrey. En Revista Moderna, año II, núm. 1 (enero de 1899), pp. 10-11.

En Poemas rústicos y Obras completas.

113a En El Estandarte, año xv, núm. 2514 (24 de febrero de 1899).

114 La musa. Parte II de A Clearco Meonio. Véase el núm. 19.

115 La noche buena. Balada. En El Estandarte, año xir, núm. 2177 (24 de diciembre de 1897).

En Obras completas con el título Nocbebuena.

115 a - En El Tiempo Ilustrado, año vir, núm. 51 (22 de diciembre de 1907), pp. 862-863.

116 La nocbe de noviembre. Fragmento. En Obras completas.

117 Nocbe rústica de Walpurgis. En El Mundo (23 de mayo de 1897), pp. 341-342.

En Poemas rústicos y Obras completas.

117 a En El Estandarte, año xiII, núm. 2008 (26 de mayo de 1897).

$117 \mathrm{~b} \longrightarrow$ En Revista Moderna, año III, núm. 1 (primera quincena de enero de 1900), pp. 2-9.

$117 \mathrm{c}$ - En El Contemporáneo, t. xII, núm. 2437 (29 de noviembre de 1906).

$117 \mathrm{~d} \longrightarrow$. En Artes y Letras, año III, núm. 43 (septiembre de 1907).

$117 \mathrm{e}-$ Obsequio de la Revista Moderna de México, en la velada celebrada en honor del poeta en el Teatro del Renacimiento. México, Imprenta de I. Escalante, 1907. 27 pp., retrato. 
$117 \mathrm{f}-$ En Revista de Revistas, año xxvi, núm. 1379 (25 de octubre de 1936).

$117 \mathrm{~g} \longrightarrow$. En Repertorio Americano, año Xxi, núm. 894, t. XxxvII, núm. 14 (8 de junio de 1940), pp. 220-222.

118 Nocbes de junio. (De V. Hugo.) En Obras completas.

119 Noctifer. Parte II de Paisajes. Véase el núm. 131.

120 Nocturno. En Obras completas.

121 Nocturno. Parte III de Procul negotiis. Véase el núm. 147.

122 Nostálgica. En Poemas rústicos y Obras completas.

123 Nupcial. Véase el núm. s1d.

124 Ocaso. A un pintor. En El Estandarte, año x, núm. 1232 (28 de agosto de 1894).

En Poemas rústicos y Obras completas.

124a - En La Revista Azul, t. I, núm. 19 (9 de septiembre de 1894), p. 292.

124b - En El Fígaro Mexicano, t. I, núm. $23\left(1^{\circ}\right.$ de mayo de $1897)$, p. 4 .

$124 \mathrm{c}$ - En El Universal, t. xrv, núm. 115 (23 de mayo de 1897).

$124 \mathrm{~d}$ - En El Contemporáneo, t. Ix, núm. 1696 (7 de abril de 1904).

124e -En Artes y Letras, año Iv, núm. 157 (27 de marzo de 1910).

125 Oda a la juventud del Instituto. En Obras completas.

126 Oda. A la memoria del ilustre potosino Florencio Cabrera. En Obras completas.

127 Ofelia. En Obras completas.

128 ¡Oh, sol! A Julio Ruelas. En Revista Moderna, año III, núm. 10 (segunda quincena de mayo de 1900), p. 153.

128 - En El Esiandarte, año xvi, núm. 2961 (5 de septiembre de 1900).

128b. - En El Contemporáneo, t. vir, núm. 1351 (19 de octubre de 1902).

$128 \mathrm{c}$ [—]. En Obras completas con el título Bajo el sol. 
129 Orillas del Papaloapan. Parte I de Frondas y glebas.

Véase el núm. 83.

130 Paganas. Véase el núm. 164.

131 Paisajes. I. Meridies. II. Noctifer. En Revista Nacional de Ciencias $y$ Letras, t. II (1889), p. 149.

En Poemas rústicos y Obras completas.

131a - A Manuel Gutiérrez Nájera. En La Revista Azul, t. II, núm. 16 (17 de febrero de 1895), p. 249.

$131 \mathrm{~b}$ - En El Fígaro Mexicano, t. I, núm. 10 (22 de enero de 1897), p. 5 .

131c En El jueves de El Mundo, núm. 23 (19 de junio de 1902), p. 12.

132 Paolo. En Obras completas.

133 Paolo y Francesca. En El Album de la Mujer, año III, t. Iv, núm. 15 (12 de abril de 1885), p. 145 .

En Obras completas.

133a - En La República Literaria, año III, t. IV (1888-1889), p. 719 .

$133 \mathrm{~b}-$ En El Mundo Literario Ilustrado (de Juan de Dios Peza), t. I, núm. 12 (12 de abril de 1891), p. 6.

$133 \mathrm{c}$ - En El Mundo Literario Ilustrado (de Juan de Dios Peza), t. III, núm. 30 (24 de julio de 1892).

$133 \mathrm{~d} \longrightarrow$. En El Mundo, t. II, núm. 6 (18 de agosto de 1895), p. 43.

$133 \mathrm{e}-$ En El Contemporáneo, t. vil, núm. 1335 (24 de agosto de 1902).

134 Para una romanza de $P$. Tosti. En El Contemporáneo, t. Ix, núm. 1997 (25 de mayo de 1905).

En Obras completas.

$134 a$ - En El Mundo Ilustrado, año xir, t. 1, núm. 15 (9 de abril de 1905).

134b - En El Estandarte, año xxI, núm. 4461 (12 de noviembre de 1905).

134c . En El Diario del Hogar, año xxvi, núm. 7855 , t. LI, núm. 85 (23 de diciembre de 1906).

134d - En Artes y Letras, año v, núm. 118 (27 de junio de 1909). 
135 El Parthenon. En Obras completas.

136 Pasión. En Obras completas.

137 Pastoral. Poema rústico. A Balbino Dávalos. En Revista Moderna, año II, núm. 8 (agosto de 1899), pp. 227-232.

En Poemas rústicos y Obras completas.

137 a . En El Estandarte, año xv, núm. 2760 (29 de diciembre de 1899).

137b - En El Contemporáneo, t. xv, núm. 3027 (28 de noviembre de 1908).

$137 \mathrm{c} \longrightarrow$. En Revista de Revistas, año xxvi, núm. 1379 (25 de octubre de 1936).

138 ¡Patria! En Obras completas.

139 El perro. En El Contemporáneo, t. Ix, núm. 1637 (21 de enero de 1904).

Parte XIX de Noche rústica de Walpurgis. Véase el núm. 117.

139 a En El Tiempo Ilustrado, año vi, núm. $30 \quad 22$ de julio de 1906), p. 390 .

140 Plegaria. En El Imparcial, año II, núm. 146 (28 de enero de 1883). En Obras completas.

141 Poema del recuerdo. En El T'iempo Ilustrado, año vi, núm. 5 (28 de enero de 1906), p. 94.

141a - A Vicente Espinosa y Cuevas. En El Estandarte, año XXI, núm. 4512 (16 de enero de 1906).

En Obras completas.

142 Poema de vida. I. Idilio. II. Epitalamio. III. Elegia. En El Mundo, t. II, núm. 4 (25 de julio de 1897).

En Poemas rústicos y Obras completas.

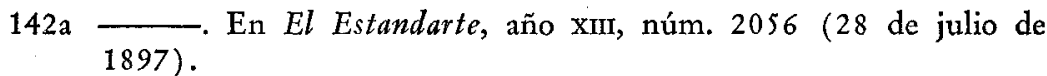

$142 \mathrm{~b} \longrightarrow$. En Revista Moderna, año III, núm. 10 (segunda quincena de mayo de 1900), pp. 164-166.

$142 \mathrm{c} \longrightarrow$. En El Tiempo, semanario ilustrado, t. III, núm. 145 (5 de octubre de 1905), pp. 514-515.

142d - En El Tiempo, año xxıv, núm. 7837 (2 de diciembre de 1906).

143 Los poetas. Parte III de A Clearco Meonio. Véase el núm. 19. 
144 Una postal. En Obras completas.

145 Postal a Josefina. En Obras completas.

146 Primavera. En Obras completas.

147 Procul negotiis. I. Matinal. II. Vespertino. III. Nocturno. A Ladislao Gómez Palacio. En El Mundo, año vi, t. I, núm. 24 (11 de junio de 1899), p. 400.

En Poemas rústicos y Obras completas.

147a - En El Estandarte, año xv, núm. 2727 (17 de noviembre de 1899).

147b - En El Contemporáneo, t. vir, núm. 1311 (10 de junio de 1902).

147c En El Contemporáneo, t. Ix, núm. 1816 (13 de octubre de 1904).

147d En El Tiempo, semanario ilustrado, t. III, núm. 145 (S de octubre de 1905), pp. 514-515.

147e - En El Tiempo, año xxıv, núm. 7837 (2 de diciembre de 1906).

148 Psalmo del fuego. A Victoriano Salado Alvarez. En El Mundo Ilustrado, año IX (23 de febrero de 1902).

En Poemas rísticos. En Obras completas con el título Salmo del fuego.

148 a - En El Estandarte, año xvir, núm. 3386 (27 de febrero de 1902).

148b —. En El Tiempo Ilustrado, t. II, núm. 63 (10 de marzo de 1902), pp. 134-135.

$148 \mathrm{c}$ - En El Contemporáneo, t. vir, núm. 1286 (2 de mayo de 1902).

148d [Revistas, año xxyI, núm. 1379 (25 de octubre de 1936).

149 Pulcherrima dea. Parte de Sonetos paganos. Véase el núm. 164.

15015 de septiembre. En Obras completas.

15.1 Recuerdo. En Obras completas.

152 Rembrandt. En un álbum. En El Contemporáneo, t. v, núm. 1093 (19 de abril de 1900).

En Obras completas. 
152a - En El Estandarte, año xvr, núm. 2851 (22 de abril de 1900).

152b - En El Contemporáneo, t. vir, núm. 1297 (13 de abril de 1902).

153 Remember. En Obras completas.

154 El río. En El Contemporáneo, t. Ix, núm. 1943 (16 de marzo de 1905).

Parte VI de Noche rústica de Walpurgis. Véase el núm. 117.

155 Rosa mystica. En El Estandarte, año xIIr, núm. 2013 (2 de junio de 1897).

En Poemas rústicos y Obras completas.

155a - En El Tiempo, año xxIv, núm. 7858 (30 de diciembre de 1906).

156 Salmo. En Obras completas.

157 Salmo del fuego. Véase el núm. 148.

158 Scherzo trágico. Fragmento de Lobreguez. Véase el núm. 102a.

159 La selva. Parte I de A Clearco Meonio. Véase el núm. 19.

160 La siesta. En El Contemporáneo, t. rx, núm. 1714 (28 de abril de 1904).

No se incluye en ninguna colección de la obra de Othón.

161 Símbolo. En Obras completas.

162 Sollozos. En Obras completas.

163 Soneto. En Obras completas.

164 Sonetos paganos. I. Pulcherrima dea. II. A un traductor de Horacio. En Revista Moderna, año in, núm. 3 (marzo de 1899), p. 74. En Poemas rústicos y Obras completas.

164a [- $]$. Publicada con los títulos Venus y A Ambrosio Ramírez en La República Literaria, año $\mathrm{IV}, \mathrm{t} . \mathrm{v}$ (1889-1890), p. 32.

164b [- ]. Publicada con el título Paganas en El Estandarte, año XV, núm. 2550 (12 de abril de 1899).

$164 \mathrm{c} \longrightarrow$. En El Contemporáneo, t. vir, núm. 1349 (12 de octubre de 1902).

164d [- ]. Publicada con el título Paganas en Artes y Letras, año III, núm. 29 (diciembre de 1906). 
165 Surgite. A Jesús Valenzuela. En El Renacimiento (29 de abril de 1894), p. 271.

En Poemas rústicos y Obras completas.

165 a - En La Revista Azul, t. IIr, núm. 11 (14 de julio de 1895), p. $169-170$.

$165 \mathrm{~b} \longrightarrow$. En El Mundo, t. Ir, núm. 5 (11 de agosto de 1895 ), p. 34.

$165 \mathrm{c}$ - En Revista Moderna, año I, núm. 10 (15 de diciembre de 1898), pp. 157-158.

$165 \mathrm{~d}-$ En El Estandarte, año xxII, núm. 4692 (30 de agosto de 1906).

$165 \mathrm{e}$ - En El Tiempo Ilustrado, año vi, núm. 37 (9 de septiembre de 1906), p. 501.

$165 \mathrm{f}$. En El Estandarte, año XXII, núm. 4771 (5 de diciembre de 1906).

$165 \mathrm{~g} \longrightarrow$. En El Contemporáneo, t. xv, núm. 2957 (3 de septiembre de 1908).

166 Tarde campestre. En Obras completas.

166a [- $[-$ Publicada con el título Tarde primaveral en Obras, 1928 , t. I.

167 Tristeza. Meditación de Lamartine. En Obras completas.

168 Tristezas. A mi madre. Véase el núm. $34 a$.

169 Urente. Soneto inédito. En El Contemporáneo, t. xIII, núms. 2657 y 2658 (20 y 30 de agosto de 1907$)$.

La última es la versión corregida.

169a - En Revista de Literatura Mexicana, año I, núm. 1 (1940), p. 24.

170 Venus. En La República Literaria, año Iv, t. v (1889-1890), p. 32. Parte de Sonetos paganos con el título Pulcherrima dea. Véase el núm. 164a.

171 Vespertino. Parte II de Procul negotiis. Véase el núm. 147.

172 Vis et vir. En Obras completas.

173 Voz interna. Véase el núm. 96. 
B. TEATRO.

174 A las puertas de la vida. Monólogo. En El Contemporáneo, t. XIII, núm. 2657 (29 de agosto de 1907).

En Obras completas.

175 La cadena de flores. Comedia en un acto. (Verso.) San Luis Potosí, 1879. 42 pp., 22 cms. Ms. La escena en Madrid.

-Francisco Monterde, Bibliografia del teatro en México, México, 1933-1934.

176 Después de la muerte. Drama en tres actos. (Verso.) Estrenado en el Teatro Alarcón de San Luis Potosí, el 30 de diciembre de 1883. San Luis Potosí, Imprenta de Dávalos, 1884, 86 pp.

-Francisco Monterde, Bibliografía del teatro en México.

En Obras completas.

$176 a$ - Reimpreso en México por la Tipografía de Mena y Villaseca en 1885 .

-Monterde, Bibliografia del teatro en México.

$176 \mathrm{~b} \longrightarrow$. Reimpreso por la Tipografía Literaria de Filomeno Mata. (Edición del Diario del Hogar), 1886.

-Monterde, Bibliografía del teatro en México.

177 Herida en el corazón y La sombra del hogar. Obras dramáticas. En El Tiempo Ilustrado, año vI, núm. 39 (29 de septiembre de 1907), p. 652 .

-Monterde, Bibliografía del teatro en México. (Dato de José López Portillo y Rojas.)

178 Lo que bay detrás de la dicba. Drama en tres actos. Estrenado en el Teatro Alarcón de San Luis Potosí, el 14 de octubre de 1886. San Luis Potosí, Imprenta de Dávalos, 1886. 68 pp. Dedicado al general Bernardo Reyes.

-Monterde, Bibliografia del teatro en México.

En Obras completas.

179 La sombra del bogar. Véase el núm. 177.

180 El último capítulo. Pieza original. Estrenada en el gran Teatro de la Paz de San Luis Potosí, el 9 de octubre de 1905, en el festival con que se celebró el tercer centenario del Quijote. San Luis Potosí, Talleres de Imprenta y Encuadernación de J. Kaiser, 1906. 34 pp., notas y advertencias a los actores.

En Obras completas.

181 Viniendo de Picos Pardos. Monólogo. A Javier Santa María.

En Obras completas. 
C. PROSA.

\section{Cuentos y novelas cortas}

182 Coro de brujas. En El Mundo Ilustrado, año x, t. r, núms. 18 y 19 (3 y 10 de mayo de 1903).

Uno de los tres cuentos dedicados a José López Portillo y Rojas. Véanse los núms. 184 y 189.

En Obras completas.

183 Dias de otoño. En Obras completas.

184 Encuentro pavoroso. En El Mundo Ilustrado, año x, t. I, núm. 17 (26 de abril de 1903), con la dedicatoria a José López-Portillo y Rojas.

En Obras completas sin la dedicatoria.

185 En la gruta de Canoas. En Obras completas.

186 El exclaustrado. A Pancho Castro. En Obras completas.

187 Una fiesta casera. En Obras completas.

188 El montero Espinosa. A Enrique Pérez Rubio. En Obras completas.

189 El nabual. En El Mundo Ilustrado, año x, t. x, núms. 20 y 21 (17 y 24 de mayo de 1903), con la dedicatoria a Jósé López-Portillo y Rojas.

En Obras completas.

189a - En Cuentos mexicanos del siglo XIX. Selección, prólogo y notas bibliográficas de José Mancisidor. México, Editorial Nueva España, S. A. [1946], pp. 478-494. (Colección Atenea, 19.)

190 Un nocturno de Chopin. En Obras completas.

191 El pastor Corydón. En El Mundo, t. Ir, núm. 10 (15 de septiembre de 1895), pp. 84-87.

En Obras completas.

$191 \mathrm{a} \longrightarrow$ En Cuentos mexicanos del siglo XIX. Selección, prólogo y notas bibliográficas de José Mancisidor. México, Editorial Nueva España, S. A. [1946], pp. 449-477.

192 El Puente de Dios. En Obras completas.

193 Recuerdos del general Martinez. En Obras completas.

194 Sobre la sierra. En Obras completas.

195 El último trovador. En la muerte de Zorrilla. En Obras completas.

19627 de abril. En Obras completas. 


\section{Miscelánea}

197 Apretón de manos. En El Estandarte, año x, núm. 1281 (25 de octubre de 1894).

Carta a Jesús L. Sánchez en loor del Teatro de la Paz.

198. Un artículo de Otbón. La espada y el puñal. En El Estandarte, año Xxi, núm. 4310 ( 9 de mayo de 1905).

199 Carta. A Enrique de Olavarría y Ferrari. Con fecha: 29 de diciembre de 1893 desde Santa María del Río.

En la cubierta, p. [4] de El Renacimiento, segunda época, entrega 1 (7 de enero de 1894).

200 Carta. A Enrique de Olavarría y Ferrari. Con fecha: 9 de abril de 1894 desde Santa María del Río.

En la cubierta, pp. [3-4] de El Renacimiento, segunda época, entrega 25 (24 de junio de 1894).

201 Carta. A Juan B. Delgado. Con fecha: Ciudad Lerdo, el 8 de agosto de 1900.

En Cartas bispanoamericanas. Selección y prólogo de Rafael $\mathrm{He}-$ liodoro Valle. México, Secretaría de Educación Pública, 1945, pp. 78-79. (Biblioteca Enciclopédica Popular, 46.)

202 Dieciséis cartas de Manuel José Otbón. En Revista de Literatura Mexicana, t. I, 1940, pp. 256-289.

Comentario de Jesús Zavala, pp. 255-256.

203 Este libro. En Obras completas.

204 Hostia. En Obras completas.

205 El padre Pagaza. En La República Literaria, año rv, t. v (marzo 1889-marzo 1890), pp. $538-542$.

206 Rosalinda. En Obras completas.

207 Soberbia bumana. En Obras completas.

208 Telón de boca. En Obras completas. 


\section{SEGUNDA PARTE - ESTUDIOS CRITICOS Y BIOGRAFICOS}

Nota: Se hallan aquí los estudios críticos más valiosos sobre Othón y unos artículos biográficos tomados de periódicos de su tiempo. No se han incluído en esta bibliografía los numerosos poemas dedicados al poeta.

Agüeros, Victoriano. Don Mamuel José Othón. (Prólogo a la colección de sus Poesías, publicadas en 1880.) En El Tiempo, edición literaria, México, Imprenta de la Biblioteca Religiosa, Histórica, Científica y Literaria, tomo I (1883-1884), núm. 32 (24 de febrero de 1884), pp. 383-387.

En Obras completas, pp. [1013]-1023.

Amézaga, Carlos G. Poetas mexicanos. Buenos Aires, Imprenta de Pablo E. Coni e hijos, 1896, pp. 327-342.

Anónimo. A las puertas de la vida. En El Contemporáneo, t. xir, núm. 2656 (28 de agosto de 1907).

- Banquete a Manuel José Otbón. En El Estandarte, año xx, núm. 4112 (4 de septiembre de 1904).

- Después de la muerte. En El Contemporáneo, t. xiv, núm. 2805 (24 de febrero de 1908).

- Fallecimiento de Manuel José Othón. En El Estandarte, año xxח, núm. 4767 (30 de noviembre de 1906).

- Los juegos florales. En El Estandarte, año xx, núm. 4120 (15 de septiembre de 1904).

- Juegos florales de San Luis Potosí. En El Estandarte, año xx, núm. 4121 (16 de septiembre de 1904).

- Manuel José Otbón. En San Luis. En El Estandarte, año xx, núm. 4108 (31 de agosto de 1904).

Manuel José Otbón en San Luis. En El Estandarte, año xx, núm. 4112 (4 de septiembre de 1904).

- Manuel J. Othón. En El Estandarte, año XxI, núm. 4478 (2 de diciembre de 1905).

Othón. En El Estandarte, año xxrr, núm. 4784 (22 de diciembre de 1906). 
Anónimo. El último capitulo. Las fiestas de Cervantes en San Luis Potosí. Una comedia de Manuel J. Otbón. En El Mundo Ilustrado, año XII, t. II, núm. 21 (19 de noviembre de 1905).

- L La velada de Othón. En Revista Moderna, t. vir, núm. 5 (enero de 1907), pp. 312-315.

Attolini, José. Manuel José Otbón y su soledad. De Precursores mexicanos del modernismo. En Revista de Revistas, año xxvi, núm. 1348 (15 de marzo de 1936), p. 47.

Bravo, Bernabé. El retiro de un poeta. En El Estandarte, año $\mathrm{x}$, núm. 1218 (10 de agosto de 1894).

Campos, Rubén M. El folklore literario de México. México, Publicaciones de la Secretaría de Educación Pública, Talleres Gráficos de la Nación, 1929, pp. 514-517.

- Manuel José Otbón. En El Contemporáneo, t. XII, núm. 2471 (11 de enero de 1907).

- "Poemas rústicos" de Manuel José Otbón. En El Estandarte, año Xxx, núm. 4347 ( 7 de julio de 1905).

- La vida de Otbón en México. En Revista de Revistas, año xxvi, núm. 1379 (25 de octubre de 1936).

Carrasco, A. G. Manuel J. Otbón. En El Mundo (16 de mayo de 1897), p. 330 .

Castro, Francisco de A. El "Himno de los bosques". Recuerdos. En El Contemporáneo, t. xv, núm. 3027 (28 de noviembre de 1908).

- Los que se fueron. Manuel José Otbón. En El Estandarte, año xxII, núm. 4774 ( 8 de diciembre de 1906).

Cuesta, Jorge. El clasicismo mexicano. En Letras de México, año v, t. III, núm. 21 (15 de septiembre de 1942), pp. 5-6.

Estrada, Genaro. Poetas nuevos de México. Antología con noticias biográficas, críticas y bibliográficas. México, Ediciones Porrúa, 1916, pp. $210-242$.

Facha, José M. Por la semana. En El Estandarte, año xv, núm. 2757 (24 de diciembre de 1899).

Fray José. Olla podrida. En El Estandarte, año x, núm. 1299 (17 de noviembre de 1894).

Gamboa, José Joaquín. Manuel José Otbón. En Artes y Letras, año II, (diciembre de 1906). 
Gómez Palacio, Ladislao. Noche rústica de Walpurgis, por Manuel José Otbón. Estudio crítico. (Para El Estandarte.) En El Estandarte, año $\mathrm{xv}$, núm. 2597 (9 de junio de 1899).

González, Héctor. Manuel José Othón en Monterrey. (Dos anécdotas del poeta potosino.) En Nuestro México, t. r, núm. 5 (julio de 1932), pp. 64 y 78.

Henríquez Ureña, Max. Desde México. En El Contemporáneo, t. xiII, núm. 2544 (13 de abril de 1907).

Junco de la Vega, Celedonio. Manuel José Othón. En El Contemporáneo, t. xII, núm. 2471 (11 de enero de 1907).

López, Rafael. Elegía. Dicha en la velada celebrada por esta "Revista" en honor de Manuel J. Othón. En Revista Moderna, t. vin, núm. 5 (enero de 1907), pp. 316-318.

López Portillo y Rojas, José. Elogio de Manuel José Otbón, leịdo en la Academia Mexicana de la Lengua en sesión especial consagrada a este objeto, la noche del 22 de mayo de 1907. México, Imprenta de Ignacio Escalante, 1907.

Medina, Francisco. Intelectuales mexicanos. Manuel José Otbón. En El Estandarte, año Xxi, núm. 4348 ( 8 de julio de 1905).

Meléndez, Concha. Signos de Iberoamérica. México, Imprenta de Manuel León Sánchez, 1936. Capítulo El poeta Manuel José Otbón, pp. 69-79.

M. M. La velada en bonor de Cervantes. En El Estandarte, año xxi, núm. 4436 (13 de octubre de 1905).

Montes de Oca y Obregón, Ignacio. Discurso que en los Juegos Florales celebrados en San Luis Potosí el 6 de abril de 1913 pronunció su mantenedor el Illmo. Señor Obispo don Ignacio Montes de Oca y Obregón. México, Imprenta I. Escalante, S. A., 1913.

Nervo, Amado. "Poemas rústicos" de Manuel José Otbón. De Notas bibliográficas en Revista Moderna, año v, núm. 18 (segunda quincena de septiembre de 1902), pp. 284-285.

NúÑez y Domínguez, José de Jesús. Cómo conoció Nicolás Rangel a Manuel José Othón. En Revista de Revistas, año xxvı, núm. 1379 (25 de octubre de 1936).

NúNẽE y Domínguez, Roberto. Con la viuda de Otbón. En Revista de Revistas, año xxvIr, núm. 1438 (12 de diciembre de 1937).

Ortiz de Montellano, Bernardo. Esquema de la literatura mexicana. En Contemporáneos, México, junio de 1931. 
Reyes, Alfonso. Los "Poemas rústicos" de Manuel José Otbón. México, Lacaud, 1910.

En Obras completas, pp. [1041]-1067.

Rivera, José P. "Poemas rústicos" de Manuel José Othón. En El Estandarte, año xvin, núm. 3531 (2 de septiembre de 1902).

Toro, Alfonso. Én memoria de Manuel José Otbón. En Revista de Revistas, año xmI, núm. 655 (1922), pp. 12-13.

- Se rectifican unos versos de Manuel José Otbón. En El Contemporáneo, t. xII, núm. 2463 (2 de enero de 1907).

Urbina, Luis G. Elogio de Manuel José Otbón. En Revista de Revistas, año XXvi, núm. 1379 (25 de octubre de 1936).

- Manuel J. Otbón. En El Mundo Ilustrado, t. II (23 de julio de 1905).

- Recuerdos de Otbón. I. Manuel José Othón en la cindad de México. II. Anécdotas de la intimidad, en Obras completas, pp. [1025]1040 .

- La vida literaria de México. Madrid, Imprenta Sáez Hermanos, 1917, pp. 252-263.

Unueta, Jesús. A Manuel José Otbón. En Revista Moderna, t. VII, núm. 5 (enero de 1907), pp. 319-323.

Usigli, Rodolfo. México en el teatro. México, Imprenta Mundial, 1932, pp. 83 y 117.

VázQuez, Jorge Adalberto. La obra lírica de Manuel José Otbón. En El Libro y el Pueblo, t. Ix, núm. 1 (1931), pp. 19-23.

Veral, Angel. Manuel José Othón. Recuerdos de su permanencia en Cerritos. En El Estandarte, año xxII, núm. 4779 (16 de diciembre de 1906).

Zavala, Jesús. Aurea carmina, floración de estrellas. En Revista de Revistas, año xxvIH, núm. 1499 (12 de febrero de 1939).

- Después de la muerte. En Revista de Revistas, año xxvir, núm. 1425 (12 de septiembre de 1937).

- Dos anécdotas ignoradas de la vida de Otbón. En Revista de Revistas, año xxvi, núm. 1379 (25 de octubre de 1936).

- Dos instantes de la vida de Otbón. En Repertorio Americano, t. XxIX-Xxx (julio de 1934 a julio de 1935), p. 89.

- En torno a la dedicatoria de los "Poemas rústicos". En Revista de Revistas, año Xxvi, núm. 1379 (25 de octubre de 1936). 
Zavala, Jesús. Epistolario de Manuel José Otbón. En Letras de México, año $v$, t. III (1s de febrero de 1941), pp. 4 y 9.

. Exodo de Manuel José Othón. En Revista de Revistas, año xxvir, núm. 1470 (24 de julio de 1938).

- Génesis del "Himno de los bosques." En Revista de Revistas, año XXvi, núm. 1379 (2S de octubre de 1936).

-. Infancia y adolescencia de M. J. Otbón. En Revista de Revistas, año xxvII, núm. 1413 (20 de junio de 1937).

- In memoriam. En Revista de Revistas, año Xxvi, núm. 1379 (25 de octubre de 1936).

- Una joya iconográfica. En Revista de Revistas, año xxvI, núm. 1418 (25 de julio de 1937).

- Juventud literaria de Manuel José Otbón. En Revista de Revistas, año Xxvir, núm. 1424 ( 5 de septiembre de 1937).

- Manuel José Otbón en 1894. En Revista de Revistas, año xxvm, núm. 1461 (22 de mayo de 1938).

- Manuel José Othón en Guadalcázar. En Revista de Revistas, año XXvir, núm. 1436 (20 de noviembre de 1937).

- Manuel José Otbón y el tercer centenario del "Quijote" en San Luis Potosí. En Revista de Revistas, año xxx, núm. 1529 (10 de septiembre de 1939).

- Noviazgo y desposorios de Manuel José Otbón. En Revista de Revistas, año xxvm, núm. 1408 (16 de mayo de 1937).

- La paz aldeana de Manuel J. Otbón. En Revista de Revistas, año xxvin, núm. 1450 (6 de marzo de 1938).

- Los postreros instantes de Manuel José Othón. En Revista de Revistas, año XXVI, núm. 1379 (25 de octubre de 1936).

- El sentido sinfónico de la poesía de Othón. En Revista de Revistas, año xxvim, núm. 1453 (27 de marzo de 1938).

- Tránsito y funerales de Manuel José Otbón. En Revista de Revistas, año xxvin, núm. 1517 (18 de junio de 1939).

- Trayectoria poética de Manuel José Otbón. En Letras de México, año Ix, t. $v$, núm. 113 ( $1^{\circ}$ de julio de 1945), p. 1.

- Viacrucis de los Poemas rústicos. En Revista de Revistas, año XxvII, núm. 1482 (16 de octubre de 1938).

- La vida errante y pueblerina de Manuel José Otbón. En Revista de Revistas, año xxvII, núm. 1431 (24 de octubre de 1937).

- La vida metropolitana de Otbón. En Revista de Revistas, año xxvIr, núm. 1488 (27 de noviembre de 1938). 